\title{
Passivation and Stabilization of Aluminum Nanoparticles for Energetic Materials
}

\author{
Matthew Flannery, ${ }^{1}$ Tapan G. Desai, ${ }^{1}$ Themis Matsoukas, ${ }^{2}$ \\ Saba Lotfizadeh, ${ }^{2}$ and Matthew A. Oehlschlaeger ${ }^{3}$ \\ ${ }^{1}$ Advanced Cooling Technologies, Inc., 1046 New Holland Avenue, Lancaster, PA 17601, USA \\ ${ }^{2}$ Penn State University, 150 Fenske Laboratory, University Park, PA 16802, USA \\ ${ }^{3}$ Rensselaer Polytechnic Institute, 110 8th Street, Troy, NY 12180, USA \\ Correspondence should be addressed to Tapan G. Desai; tapandesai06@gmail.com
}

Received 17 June 2015; Accepted 13 October 2015

Academic Editor: Paulo Cesar Morais

Copyright (C) 2015 Matthew Flannery et al. This is an open access article distributed under the Creative Commons Attribution License, which permits unrestricted use, distribution, and reproduction in any medium, provided the original work is properly cited.

In aircraft applications, fuel is used not only as a propellant but also as a coolant and improving both the thermal conductivity and combustion enthalpy of the fuel is beneficial in these applications. These properties can be enhanced by dispersing aluminum nanoparticles into the fuel; however, the nanoparticles require stabilization from agglomeration and passivation from oxidation in order for these benefits to be realized in aircraft applications. To provide this passivation and stabilization, aluminum nanoparticles were encapsulated with a coating by the plasma enhanced chemical vapor deposition (PE-CVD) method from toluene precursors. The thermal conductivity, combustion and ignition properties, and stability of the nanoparticles dispersed in RP- 2 fuel were subsequently evaluated. In addition, the effect of dispersing aluminum nanoparticles in RP-2 fuel on the erosion rate of fuel nozzles was evaluated. The dispersion of PE-CVD coated aluminum nanoparticles at a concentration of $3.0 \%$ by volume exhibited a $17.7 \%$ and $0.9 \%$ increase in thermal conductivity and volumetric enthalpy of combustion, respectively, compared to the baseline RP- 2 fuel. Additionally, particle size analysis (PSA) of the PE-CVD coated aluminum nanofuel exhibited retention of particle size over a fivemonth storage period and erosion testing of a $1 \mathrm{~mm}$ stainless steel nozzle exhibited a negligible $1 \%$ change in discharge coefficient after 100 hours of testing.

\section{Introduction}

Increasing the mission capability of aircraft is a never ending objective for the military. Critical to achieving this objective is improving the thermal performance and energy density of the fuel aboard the aircraft, which is used as both a propellant and coolant [1]. Thus, improving the thermal conductivity and energy density of the fuel is one way to reach this objective. The improvement in thermal conductivity of oil-based fluids has been demonstrated by dispersing metallic nanoparticles into the base fluid in numerous research efforts [2]. Additionally, metals have higher combustion energy than carbon based fuels [3]. Thus, creating a metallic nanofuel for aircraft applications can improve both the thermal performance and combustion energy of the fuel to meet the objective of increasing mission capability.

Due to its low density compared to other metals and larger combustion enthalpy than the base fuel [4], aluminum is a preferred candidate nanoparticle for the development of nanofuels. The improvement in the volumetric enthalpy of combustion of ethanol by Jones et al. shows that additions of $50 \mathrm{~nm}$ diameter aluminum nanoparticles at concentrations ranging from 1 to $10 \%$ by volume exhibited improvements in the volumetric enthalpy of combustion up to $15 \%$. This increase in heat release upon combustion was also demonstrated by Mitchell et al. for aluminum nanoparticle/diesel fuel systems [5]. Despite the potential for combustion improvements, the aluminum rapidly oxidizes to form aluminum 


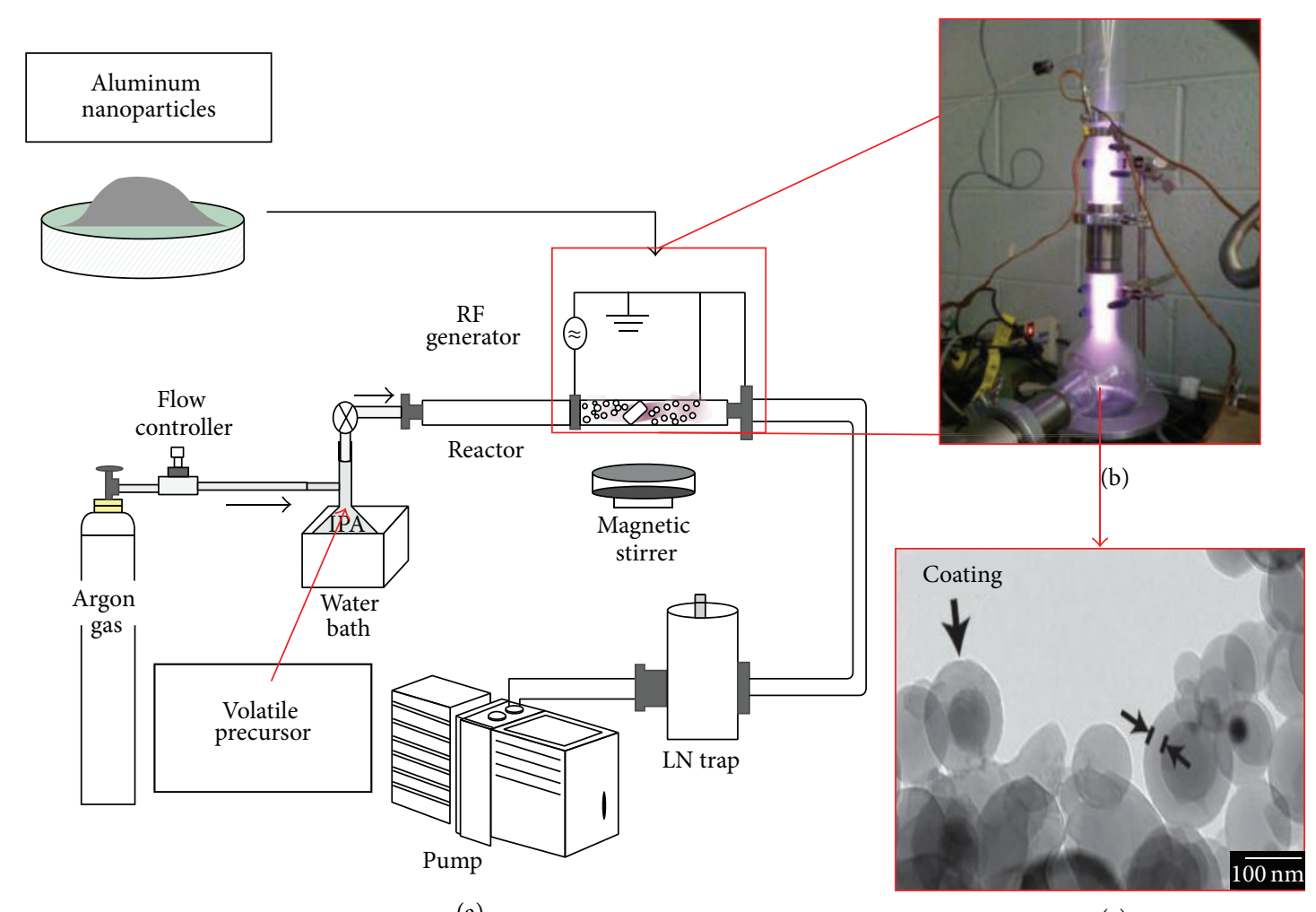

(a)

(c)

FIGURE 1: PE-CVD coating process wherein metallic nanoparticles are coated by a deeply fragmented volatile organic precursor.

oxide, which reduces the combustion enthalpy of the nanoparticles. Additionally, in the dispersed phase, the aluminum nanoparticles can agglomerate due to strong attractive forces and increase the average particle size of the aluminum, which causes the subsequent settling of the nanoparticles. This not only reduces the stability of the nanofuel, but could increase the erosion damage of fuel system components.

Reduction from agglomeration can be accomplished by a combination of electrostatic and steric stabilization [6], which can be achieved by the use of surfactants, coatings, or ionic fluids. The surface agents acting to stabilize the nanoparticles from agglomeration simultaneously protect the nanoparticle from oxidation. Meziani et al. developed stabilized aluminum nanoparticles in organic solvents using a wet-chemical synthesis approach from alane precursors with carboxylic acid molecules for surface passivation. These methods demonstrated an average aluminum particle size of $48 \mathrm{~nm}$ with a $15 \mathrm{~nm}$ standard deviation and low oxygen concentration consistent with passivation from oxidation [7]. While the wet-chemical approach has been shown to produce small diameter nanoparticles that are stabilized and passivated during synthesis $[7,8]$, application of passivating and stabilizing coatings has been conducted in the dry state [9].

To prevent the oxidation and agglomeration of the aluminum nanoparticles, the PE-CVD coating method was utilized to develop a $6 \mathrm{~nm}$ thick coating that encapsulates individual metallic nanoparticles. This coating passivates the aluminum nanoparticle to protect from oxidation and reduces the strong attractive forces to weak attractive forces to eliminate agglomeration, thereby stabilizing the nanofuel. Through previous research, this coating method has demonstrated the successful passivation of aluminum, which increased the combustion enthalpy of the aluminum [9]. In this research effort, we present the coating of aluminum nanoparticles by the PE-CVD coating method, the evaluation of the stability of the nanofuel over a 5-month period by particle size analysis (PSA), and the evaluation of the thermal conductivity and combustion enthalpy of the nanofuel at concentrations of $0.7 \%, 1.5 \%$, and $3.0 \%$ by volume by the transient hot-wire method and bomb calorimetry, respectively. Additionally, the erosion rate of a $1 \mathrm{~mm}$ stainless steel nozzle with aluminum nanofuel pumped at 200 PSID for 100 hours was evaluated in a custom built pumped loop, and the ignition delay time of the aluminum nanofuel was measured by spray injection of the fuel into an electrically heated, constant volume combustion chamber.

\section{Materials and Methods}

2.1. PE-CVD Coating Deposition. The PE-CVD coating process is a dry, one-step coating method that applies a nanometer thin plasma coating to the surface of the aluminum nanoparticles, which is outlined in Figure 1.

As is shown in Figure 1(a), the PE-CVD process is comprised of a volatile organic precursor, which is carried by inert argon gas to a plasma reaction chamber that contains aluminum nanoparticles (99.9\% purity, $80 \mathrm{~nm}$ diameter particles from Nanostructured and Amorphous Materials, Inc., 
Houston, TX). The toluene precursor is deeply fragmented by radio frequency (RF) glow discharge, as depicted in Figure 1(b). The deeply fragmented precursors react on the surface of the nanoparticles creating a coating that mimics the chemistry of the initial precursor material [10]. The volatile organic precursor chosen for this research effort was toluene due to its chemical similarity to RP-2 fuel. In order to achieve uniform coating, as is shown in Figure 1(c), the aluminum nanoparticles are agitated by a magnetic stirrer. The growth of the coating is linear with respect to time, and therefore, it is controlled by adjusting the residence time of the nanoparticles in the reaction chamber. The target coating thickness of the toluene PE-CVD coating was $6 \mathrm{~nm}$ and was confirmed by transmission electron microscopy (TEM).

2.2. Nanoparticle Storage Stability Evaluation. To evaluate the stability of the aluminum nanofuel, the particle size distribution of PE-CVD coated aluminum nanofuel samples at concentrations of $0.7 \%$ by volume was evaluated after initial dispersion in RP-2 fuel and was reevaluated in onemonth intervals for five months. At each month interval, the samples were sonicated and well mixed, and an aliquot of the nanofuel was analyzed by dynamic light scattering (DLS). A baseline nanofuel sample produced from uncoated aluminum nanoparticles at equivalent concentration was evaluated to determine whether the coating provided stability from agglomeration during the five-month storage period.

Additionally, to evaluate the ability to redisperse the aluminum nanoparticles after the first month of storage, the particle size distribution of an aliquot of PE-CVD coated and uncoated aluminum nanofuel was evaluated with and without sonication.

2.3. Nanofuel Thermal Conductivity Measurements. The thermal conductivity of the aluminum nanofuel was evaluated by the transient hot-wire method. The transient hot-wire apparatus consists of a thin diameter platinum wire, as is shown in Figure 2, immersed in a stagnant fluid sample. Current is passed through the wire generating heat and the temperature of the wire is monitored throughout the duration of the test by measuring the electrical resistance of the wire.

The temperature of the wire was determined through the resistance-temperature relationship of platinum. The working equation of the transient hot-wire test is presented in (1), where $q$ is the applied electrical power to the wire, $k$ is the thermal conductivity of the fluid, $\Delta T$ is the temperature change of the wire, $t$ is time, $\alpha$ is the thermal diffusivity of the fluid, $r$ is the radius of the wire, and $C$ is a constant of the apparatus [11]:

$$
T(t)-T_{\text {ref }}=\Delta T=\frac{q}{4 \pi k} \ln \left(\frac{4 \alpha t}{r^{2} C}\right) .
$$

Equation (1) demonstrates that plotting $\Delta T$ versus $\ln (t)$ produces a linear plot which can be fitted to determine the thermal conductivity of the fluid. However, prior to analyzing nanofuel samples, the constant of the transient hot-wire test

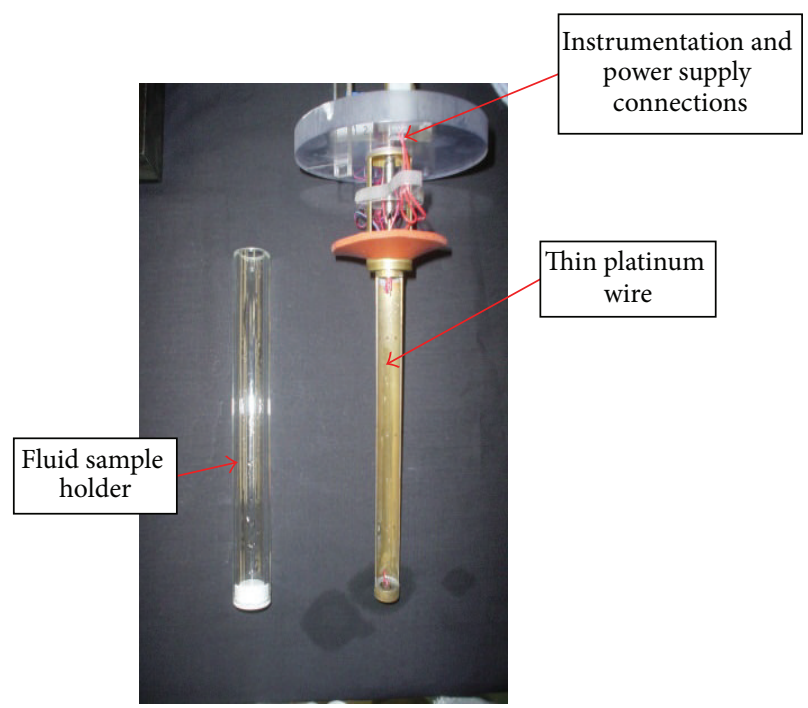

FIGURE 2: Transient hot-wire apparatus for evaluating the thermal conductivity of nanofuels.

apparatus, $C$, in (1), was determined by calibrating the apparatus with baseline RP-2 fuel using a thermal conductivity of $0.15 \mathrm{~W} / \mathrm{mK}$.

A programmable potentiostat was used to apply power and record electrical data in the transient hot-wire test apparatus, and the data was processed to calculate the thermal conductivity of the nanofuel. The potentiostat was programmed to conduct six consecutive runs in a single trial, which enables the thermal conductivity to be observed over a fiveminute time period. This method not only measured the absolute thermal conductivity of the nanofuel but also provided indication of the stability of the PE-CVD coated aluminum nanoparticles.

2.4. Combustion Enthalpy Evaluations. To quantify the increase in combustion energy of the PE-CVD coated aluminum nanofuel, the volumetric enthalpy of combustion was evaluated by bomb calorimetry. The evaluations were conducted at concentrations of $0.7 \%, 1.5 \%$, and $3.0 \%$ by volume using a Parr 1341 oxygen bomb calorimeter. To evaluate the ability of the coating to passivate the aluminum nanoparticles from oxidation, the volumetric enthalpy of combustion of baseline uncoated aluminum nanoparticles dispersed in RP-2 fuel at equivalent concentrations was evaluated.

Prior to evaluating the combustion energy of nanofuel samples, the heat capacity of the bomb calorimeter was determined using National Institute of Standards and Technology (NIST) certified benzoic acid tablets. Additionally, combustible gelatin capsules were used to handle the liquid nanofuel samples and the combustion energy of the capsules was evaluated prior to conducting combustion energy evaluations on nanofuel samples.

2.5. Nozzle Erosion Testing. Adding aluminum nanoparticles to RP-2 fuel to increase the thermal conductivity and combustion energy presents risks to erosion of fuel system 


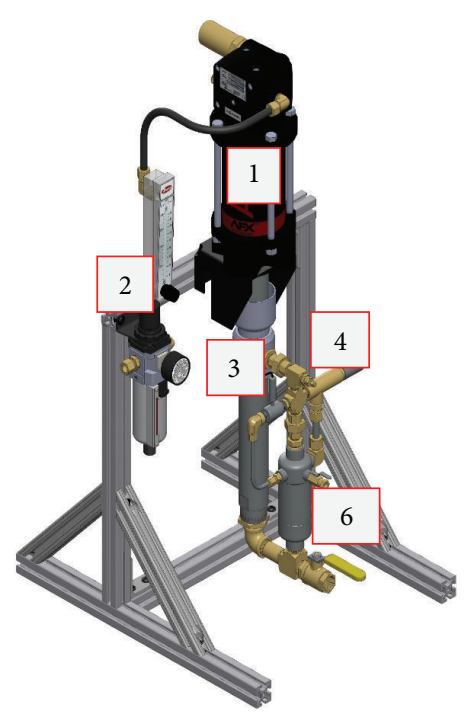

(a)

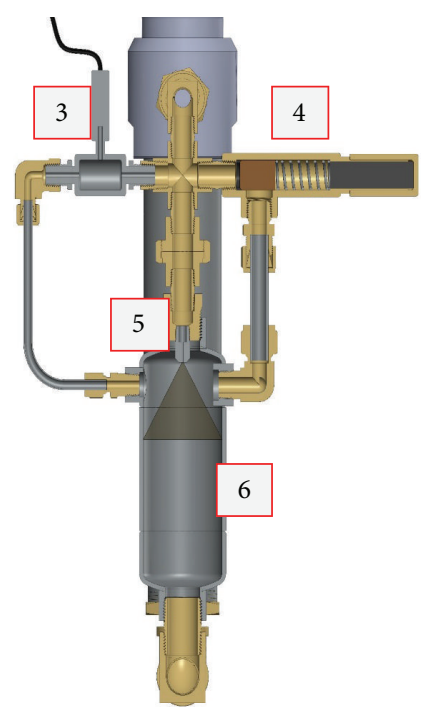

(b)

Figure 3: (a) CAD model of custom nozzle erosion pumped loop. (b) Cross section of the nozzle and reservoir. (1) Air Driven Piston Pump, (2) Air Pressure Regulator and Flow Meter, (3) High-Accuracy Differential Pressure Sensor, (4) Adjustable Pressure Relief Valve, (5) 1 mm stainless steel nozzle, and (6) Nanofuel Reservoir.

components. The most vulnerable area was suspected to be the injectors where the nanofuel is forced through a small diameter orifice and atomized. Nanofluids that are unstable will agglomerate during storage and when pumped through the nozzle could severely erode the nozzle or even clog the nozzle. To evaluate the effect of the addition of PE-CVD coated aluminum particles to RP-2 fuel, a custommade pumped loop was designed and fabricated to pump the PE-CVD coated nanofuel at a concentration of $0.7 \%$ by volume through a $1 \mathrm{~mm}$ stainless steel nozzle at 200 PSID for 100 hours, as shown in Figure 3.

The nozzle erosion pumped loop was designed with an Air Driven Piston Pump that delivered nanofuel to a removable $1 \mathrm{~mm}$ nozzle. A differential pressure transducer was connected to the inlet and outlet of the nozzle to measure and monitor the differential pressure across the nozzle. A pressure relief valve was incorporated into the pumped loop to ensure fluid bypass in the event of clogging.

Erosion of the nozzle would cause a change in the flow characteristics of the nozzle. Thus, a nozzle evaluation loop was developed, as shown in Figure 4, to measure the discharge coefficient of the nozzle at 25 -hour intervals. Additionally, optical microscopy evaluations were conducted to measure the diameter of the nozzle and observe the nozzle for signs of erosion.

At 25-hour intervals, the nozzle was removed from the erosion test pumped loop, cleaned thoroughly in acetone, and placed into the nozzle evaluation loop. Water was pumped through the nozzle at flow rates varying from $2.5 \mathrm{GPH}$ to $15 \mathrm{GPH}$ in $2.5 \mathrm{GPH}$ increment and the pressure differential across the nozzle at steady state was measured. The flow performance and erosion of the nozzle were compared to a baseline RP-2 fuel tested for 100 hours under the same

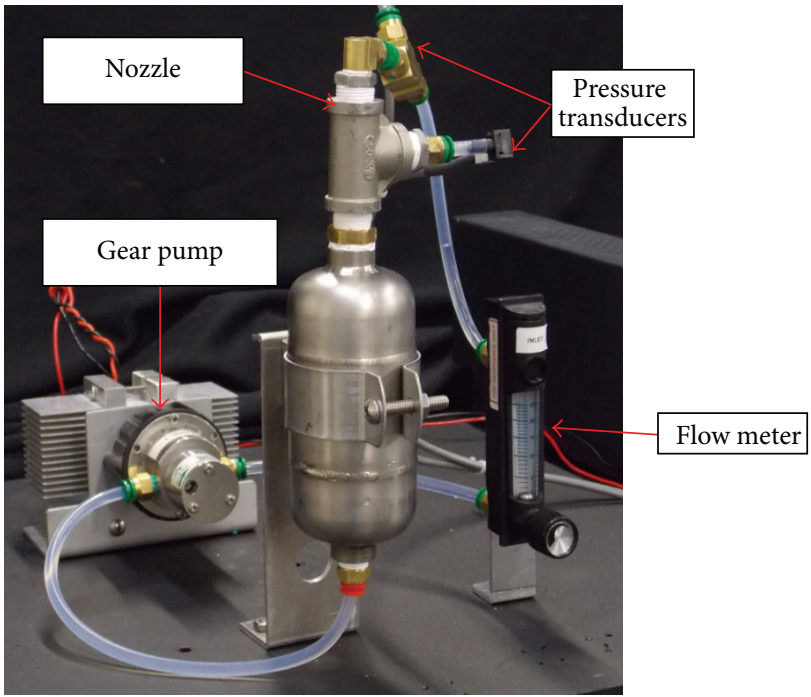

FIgURE 4: Nozzle evaluation test loop developed to characterize the discharge coefficient of the nozzle at 25-hour intervals.

condition in order to determine how the addition of metallic nanoparticles effects the erosion of fuel system components.

2.6. Ignition Delay Time Measurements. To evaluate the effect of the addition of the aluminum nanoparticles on the combustion kinetics of the fuel, the ignition delay time of baseline RP-2 fuel, uncoated aluminum nanofuel, and PE-CVD coated aluminum nanofuel, each at a concentration of $1.5 \%$ by volume, was evaluated in a constant volume, electrically heated combustion chamber, shown in Figure 5. 

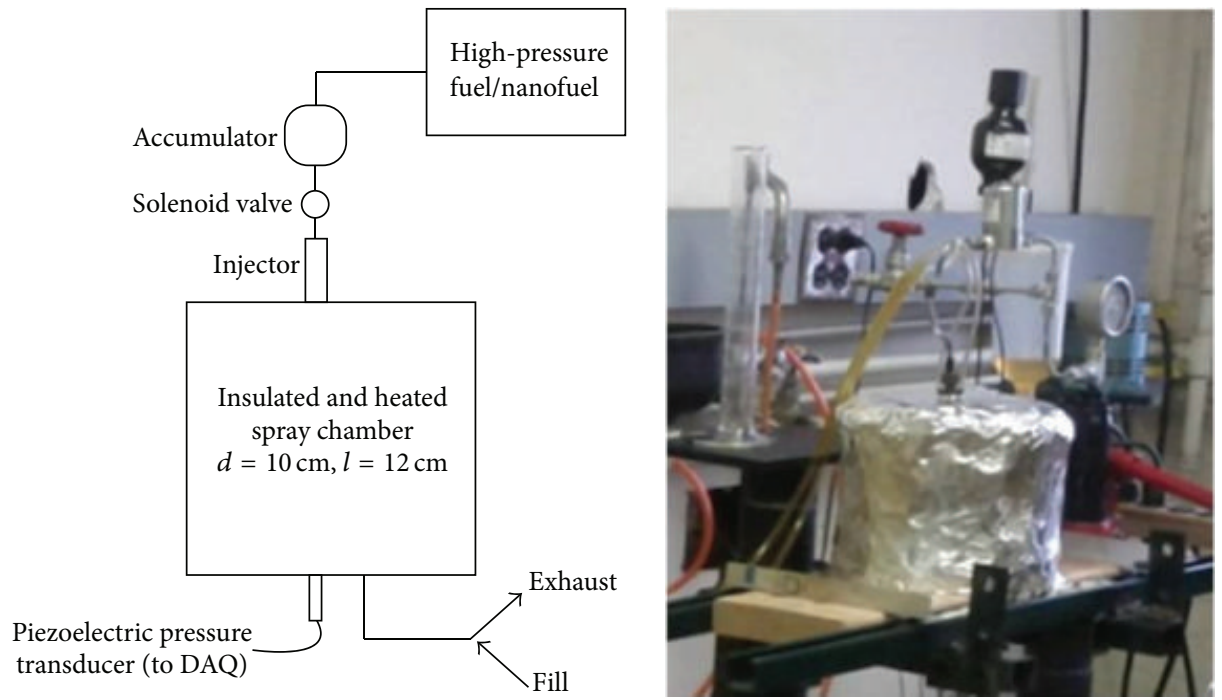

FIGURE 5: Spray combustion apparatus for evaluating the ignition delay time of RP-2 fuel and aluminum nanofuel.

The combustion chamber was heated with electric-resistance heaters embedded into the chamber walls and was insulated with $5 \mathrm{~cm}$ of high-temperature ceramic fiber, mineral wool insulation. The chamber was instrumented with $\mathrm{K}$ type thermocouples for chamber wall temperature measurements and a water-cooled Kistler pressure transducer (model 6041A) for measurement of chamber pressure during the spray ignition event and determination of the ignition delay time. At the top of the cylindrical combustion chamber, a low-pressure diesel, single-hole, pintle-style injector (Bosch W0133-1827210) atomized the fuel samples into the chamber. The injector was cooled by circulating diesel fuel, which flows through the injector body. The fuel sample was pressurized in a hydraulic accumulator, and the duration of injection was controlled by a solenoid valve located between the highpressure accumulator and the injector. The pressure of the fuel delivered to the injector was set to 2200 psia for a duration of $3 \mathrm{~ms}$.

Prior to ignition delay time measurements, the mass of the fuel injected was characterized to ensure consistent injector performance. High-pressure fuel was injected into a container and the mass of single injections was measured over ten trials using a high-accuracy scale (Mettler PM6100). The mass per injection for the three fuel samples studied is presented in Figure 6.

As is shown in Figure 6, the mass of fuel injected with a 2200 psia injection pressure and a $3 \mathrm{~ms}$ pulse duration was consistent over the 10 trials and deviated by less than $3 \%$ between fuel samples. Additionally, the consistent injection performance between the baseline RP-2 fuel and the nanofuel samples demonstrated that injector performance was not affected by the addition of toluene PE-CVD coated aluminum nanoparticles.

To carry out a series of spray ignition delay time measurements, the combustion chamber was heated to a temperature of approximately $800 \mathrm{~K}$, and the heaters were turned off. As the combustion chamber cooled over the course of several

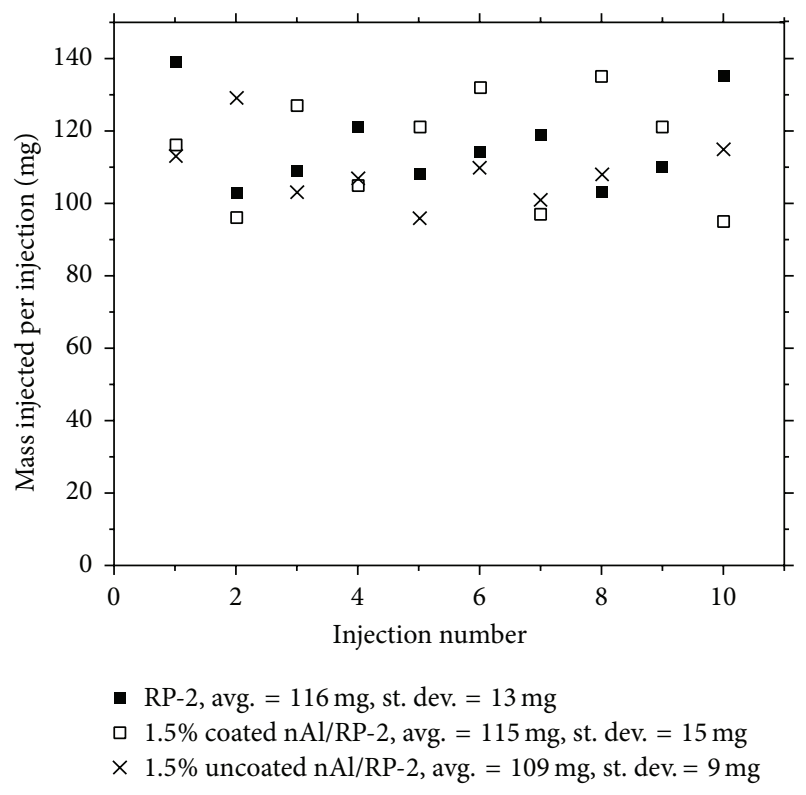

FIGURE 6: Characterization of fuel mass injection during spray combustion testing demonstrating consistent spray performance.

hours, spray injection measurements were conducted at temperatures ranging from 800 to $600 \mathrm{~K}$ with a temperature uniformity of $\pm 3 \mathrm{~K}$. The evacuated chamber was filled with high-purity air to $20 \mathrm{~atm}$ from a compressed gas cylinder, and the fuel sample was injected into the high-temperature, high-pressure air, which initiates the combustion experiment. The pressure of the chamber was monitored using a Kistler pressure transducer, as shown in Figure 7.

As is shown in Figure 7, at injection, the pressure in the chamber immediately decreases due to evaporative cooling of the chamber air as the fuel evaporates in the chamber and mixes. After an induction period, a partially mixed fuel/air 


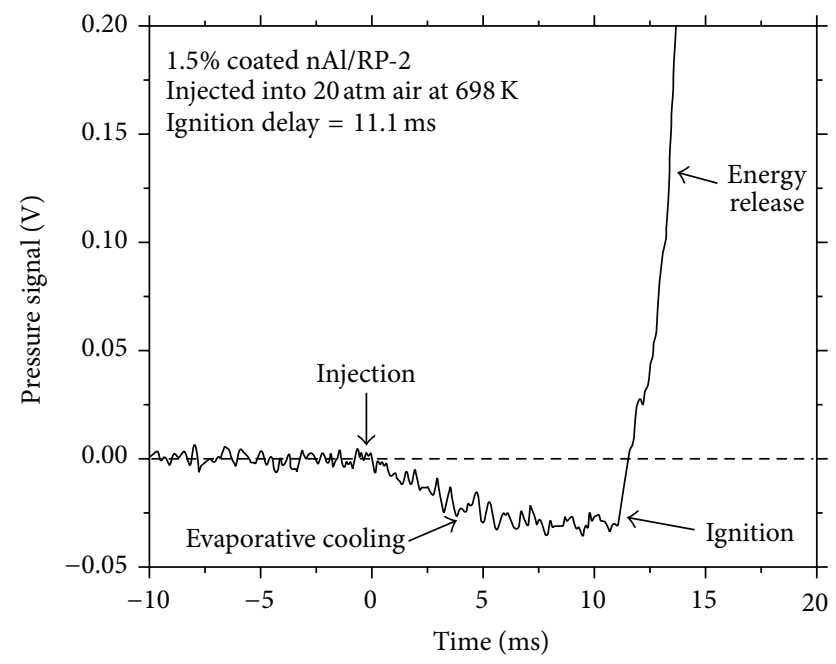

FIGURE 7: Sample pressure profile for spray ignition delay measurements.

region locally ignites causing the chamber pressure to rise rapidly. The ignition delay time was determined by comparing the time interval between spray injection, defined as the time at which the chamber pressure first decreases due to spray evaporation, and the onset of ignition, defined as the time at which the pressure gradient first becomes positive due to ignition-related heat release.

\section{Results and Discussion}

3.1. PE-CVD Coating Deposition. The target coating thickness of the PE-CVD coating from toluene precursor was $6 \mathrm{~nm}$. To ensure the coating thickness met this target and encapsulated individual nanoparticles, the coating thickness of dry aluminum nanoparticles was characterized by transmission electron microscopy (TEM). As is shown in Figure 8, the toluene PE-CVD coating encapsulates the individual aluminum nanoparticles and has an average thickness of $6.21 \mathrm{~nm}$, which demonstrates that PE-CVD coating met the target coating thickness specification.

3.2. Nanoparticle Stability Evaluation. During storage, nanoparticles will settle due to the relative density of the particle and the base fuel. However, a stabilized nanofluid will redisperse after settling without increasing particle size (i.e., will not agglomerate). The ability to redisperse the PE-CVD coated aluminum nanofuels compared to the uncoated counterpart was evaluated by measuring the median particle size with and without sonication of the respective sample by dynamic light scattering (DLS) after one month of storage at room temperature.

As is shown in Figure 9, the PE-CVD coated nanofuel sample increases particle size over the one-month period but is easily redispersed with sonication. This indicates that weak bonding forces are present between agglomerated aluminum nanoparticles. Alternatively, the uncoated aluminum nanofuel sample demonstrated a consistent particle size that

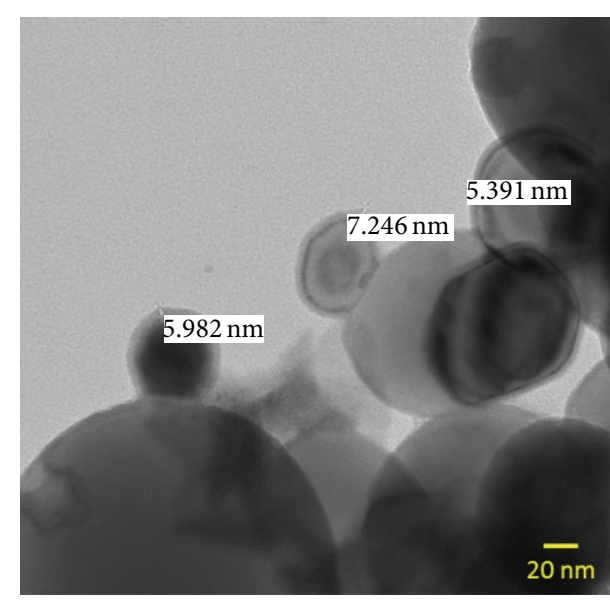

FIGURE 8: TEM micrograph of toluene PE-CVD coated aluminum nanoparticles exhibiting a $6 \mathrm{~nm}$ coating thickness that encapsulates individual aluminum nanoparticles.

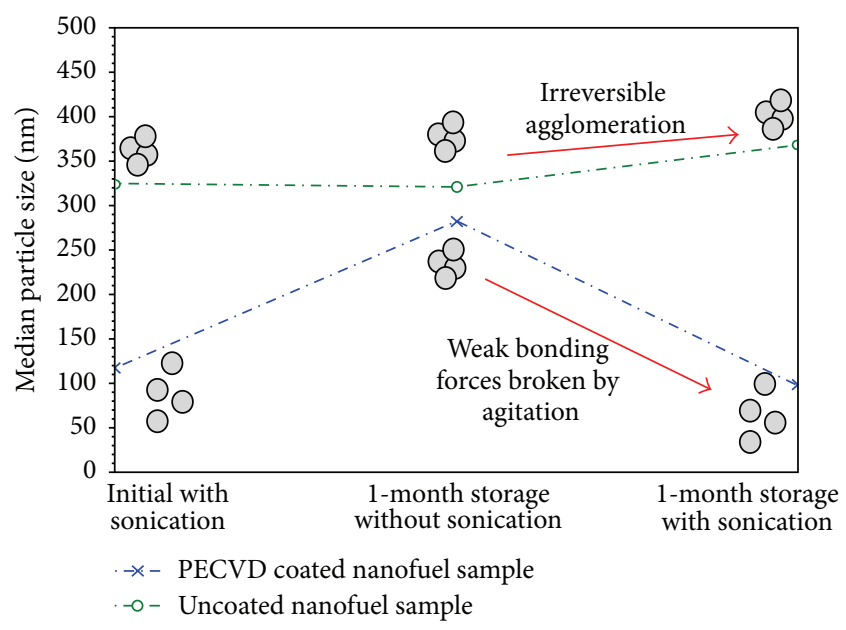

FIGURE 9: Median particle size of PE-CVD coated and uncoated aluminum nanofuel after one month of storage before and after sonication demonstrating that the PE-CVD coated nanoparticles are able to be redispersed.

could not be redispersed due to strong bonding forces between aluminum nanoparticles which leads to agglomeration. The ability to redisperse the PE-CVD coated aluminum nanofuel sample by sonication demonstrates that the coating provides stabilization from agglomeration, which improves storage stability of the nanofuel.

In order to quantify the extent of agglomeration of PECVD coated and uncoated aluminum nanoparticles, dynamic light scattering (DLS) was conducted to evaluate the particle size distribution of each sample. Particle size distributions were determined by the number of particles of a given diameter. Moreover, the samples were stored at room temperature and the DLS analysis was repeated at one-month intervals over a 5-month period to determine the growth rate of particle size due to agglomeration. DLS results at the one-month intervals are presented in Figure 10. 


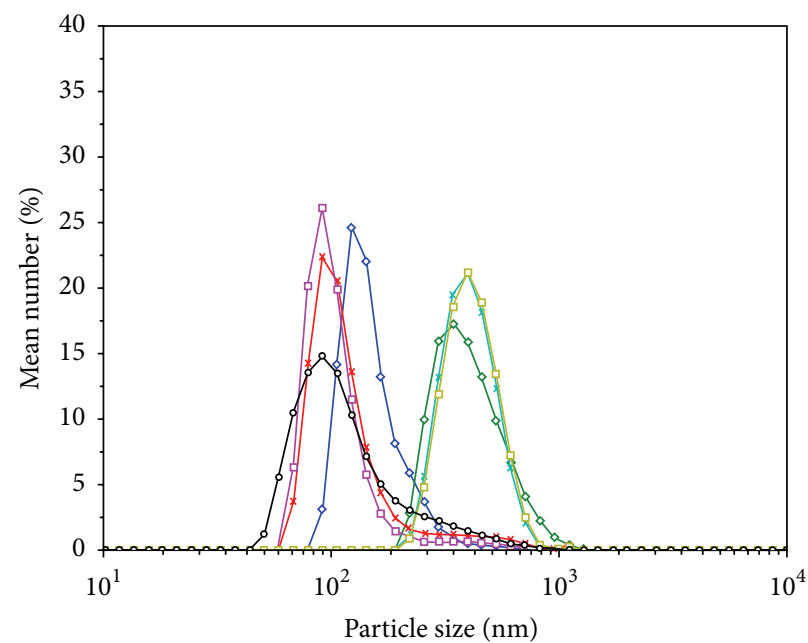

$$
\begin{aligned}
& \multimap \text { PECVD coated } t=0 \text { months } \rightarrow \text { PECVD coated } t=2 \text { months } \\
& \multimap \text { Uncoated } t=0 \text { months } \quad \square \text { Uncoated } t=2 \text { months } \\
& \rightarrow \text { PECVD coated } t=1 \text { month } \multimap \text { PECVD coated }=5 \text { months } \\
& \text { * Uncoated } t=1 \text { month }
\end{aligned}
$$

FIGURE 10: Dynamic light scattering results of PE-CVD coated and uncoated aluminum nanoparticles dispersed in RP-2 fuel demonstrating that the PE-CVD coated nanofuel maintained a reduced median particle size over a five-month storage period.

As is shown in Figure 10, the smallest nanoparticle size present in the uncoated sample distribution was greater than $200 \mathrm{~nm}$, while the PE-CVD coated aluminum nanoparticle distribution exhibited the smallest aluminum nanoparticle size at $\sim 80 \mathrm{~nm}$. Moreover, the median particle size of the PE-CVD coated aluminum nanoparticle sizes was $\sim 150 \mathrm{~nm}$, which was $30 \%$ of the median particle size of the uncoated counterpart. After being stored for five months at room temperature, the PE-CVD coated aluminum nanoparticles maintained a smaller particle size than the uncoated counterpart sample with $90 \%$ of the particles being less than $235 \mathrm{~nm}$ in diameter indicating that the PE-CVD coating prevents agglomeration of the aluminum nanoparticles.

3.3. Nanofuel Thermal Conductivity Measurements. The thermal conductivity of PE-CVD coated aluminum nanofuel samples at a concentration of $0.7 \%, 1.5 \%$, and $3.0 \%$ by volume was determined by the transient hot-wire method in nine trials spanning a three-month period and results are presented in Figure 11. The measured thermal conductivity was plotted with the upper and lower bounds of the Hashin and Shtrikman (H-S) model for thermal conductivity in nanofluids, which is presented in (2), where $k_{\mathrm{f}}$ is the thermal conductivity of the base fluid RP-2 fuel, $k_{\mathrm{p}}$ is the thermal conductivity of the aluminum particle, $\phi$ is the volume fraction of nanoparticles, $[k]=k_{\mathrm{p}}-k_{\mathrm{f}}$, and $k_{\mathrm{nf}}$ is the thermal conductivity of the nanofuel [12]:

$$
\begin{gathered}
k_{\mathrm{f}}\left[1+\frac{3 \phi[k]}{3 k_{\mathrm{f}}+(1-\phi)[k]}\right] \leq k_{\mathrm{nf}} \\
\quad \leq\left[1-\frac{3(1-\phi)[k]}{3 k_{\mathrm{p}}-\phi[k]}\right] k_{\mathrm{p}} .
\end{gathered}
$$

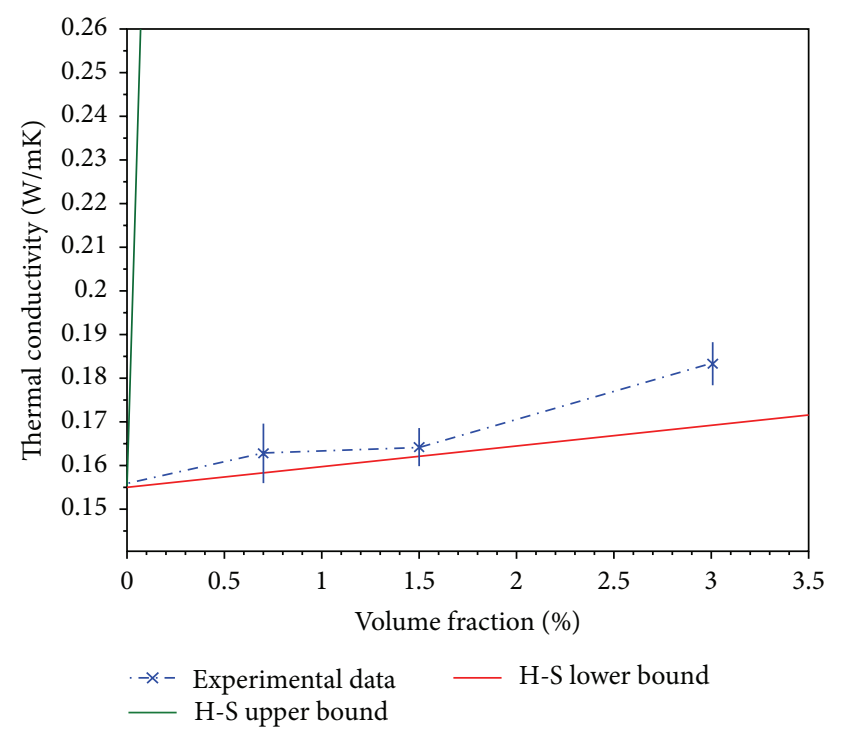

FIGURE 11: Thermal conductivity of PE-CVD coated aluminum nanoparticles dispersed in RP-2 fuel at $0.7 \%, 1.5 \%$, and $3.0 \%$ volume fractions.

As is shown in Figure 11, the thermal conductivity of PECVD coated aluminum nanofuel increases with increasing nanoparticle concentration and reaches a $17.7 \%$ improvement in thermal conductivity over the baseline RP-2 fuel at a 3.0\% volume fraction. The error bars in Figure 11 represent one standard deviation in the thermal conductivity measured over multiple trials. This indicates that addition of aluminum nanoparticles improves the thermal performance of RP-2 fuel and, as a result, increases the heat transfer properties of the fuel as a coolant. Furthermore, agreement of the thermal conductivity of the PE-CVD coated aluminum nanofuel samples with the lower bound of the H-S model indicates that there is no anomalous improvement in thermal performance. The well-known $\mathrm{H}-\mathrm{S}$ model bounds the thermal conductivity of a nanofluid based on the configuration of the nanoparticles. The lower bound of the model corresponds to a nanofluid configuration in which the nanoparticles are discretely dispersed, while the upper bound of the model corresponds to a nanofluid configuration in which nanoparticles form chains that increase the thermal conduction path, as shown in Figure 12 [12]. The agreement with the lower bound of the $\mathrm{H}-\mathrm{S}$ model provides supporting evidence that the PE-CVD coated aluminum nanofuels have increased stability that can be attributed to lack of agglomeration and support the PSA results presented in Figure 10.

As nanoparticles settle, the thermal conductivity of the nanofuel will decrease, approaching that of the RP-2 fuel. Hence, a consistent thermal conductivity throughout the six consecutive runs indicates a low settling rate and demonstrates a stable nanoparticle suspension. The experimentally determined thermal conductivity of six consecutive runs for the RP-2 baseline, $0.7 \%, 1.5 \%$, and $3.0 \%$ by volume PE-CVD coated aluminum nanofuel is presented in Figure 13.

As is shown in Figure 13, the thermal conductivity of the nanofuel samples is consistent over six consecutive runs, 


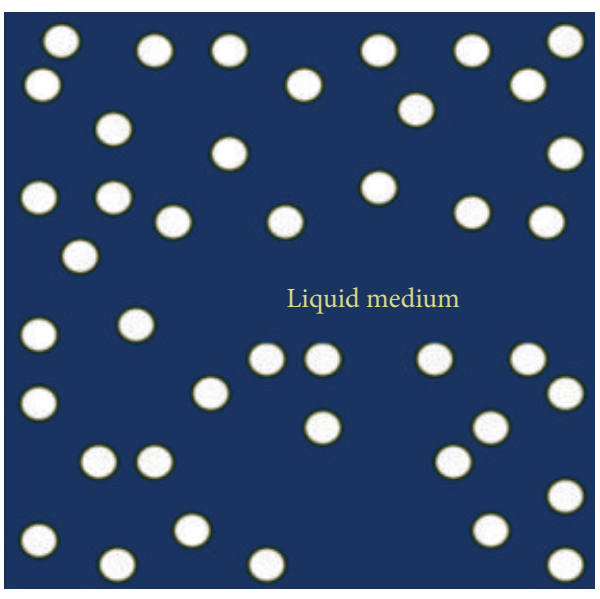

(a)

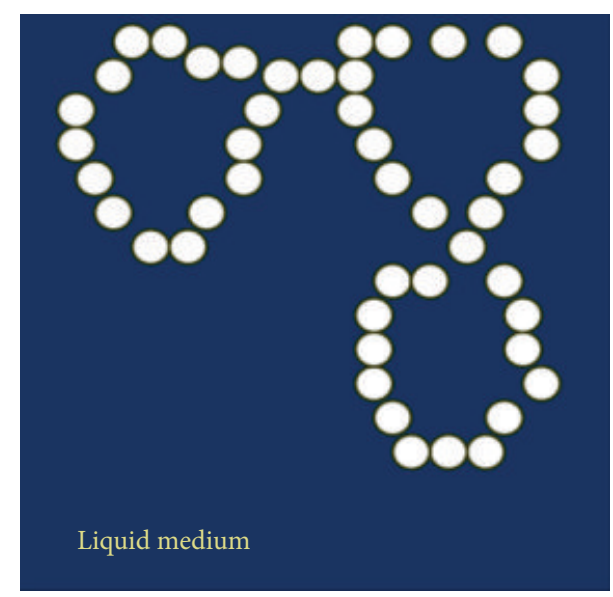

(b)

FIGURE 12: Depiction of nanoparticle configurations that correspond to the (a) lower bounds and (b) upper bounds of the H-S model [12].

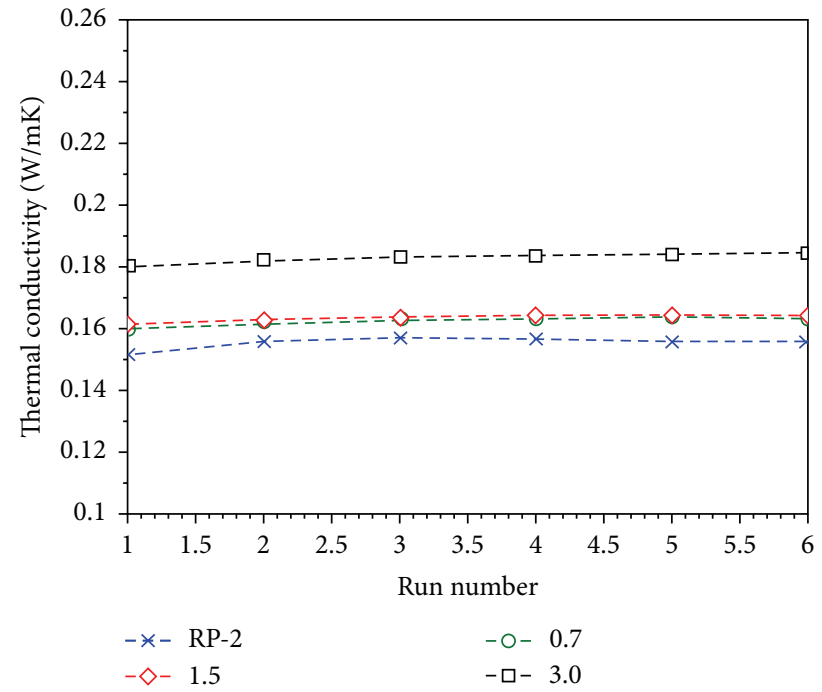

FIGURE 13: Thermal conductivity measurements of baseline RP-2, $0.7 \%, 1.5 \%$, and $3.0 \%$ PE-CVD coated aluminum nanofuel over six consecutive runs spanning a five-minute period exhibiting consistent thermal conductivity and indicating low settling rate of the aluminum PE-CVD nanoparticles.

which indicates a low settling rate. The consistent thermal conductivity between consecutive runs provides evidence to support enhanced stabilization of the PE-CVD coated aluminum nanoparticles.

PE-CVD coated aluminum nanoparticle stability in storage conditions was also determined by repeating the thermal conductivity analysis over three consecutive months. Agglomerating nanoparticles will increase the diameter of the nanoparticles causing them to settle out of solution, which reduces the thermal conductivity of the nanofuel, according to the H-S model. Consistent thermal conductivity readings

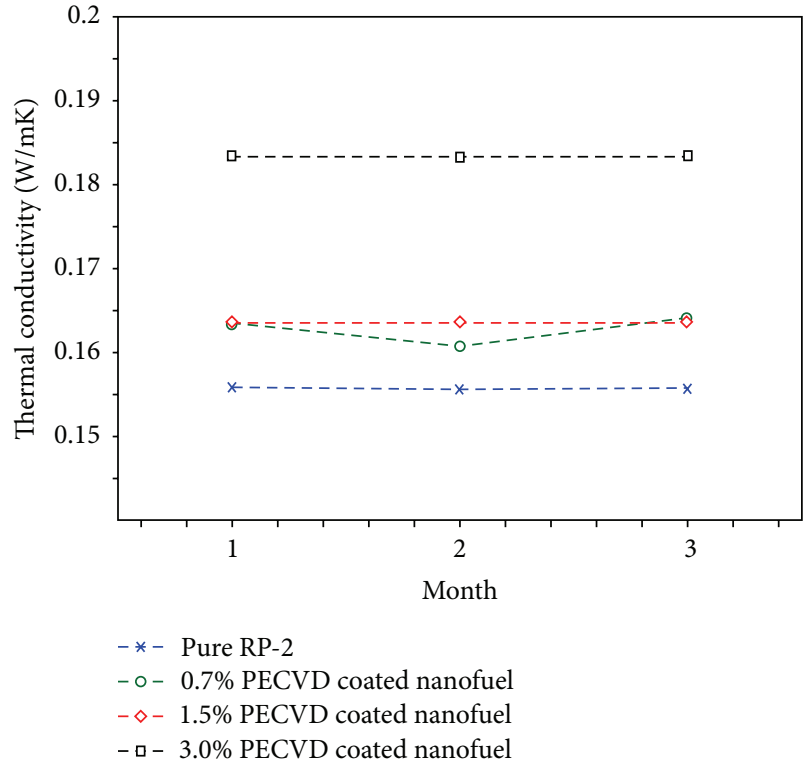

FIGURE 14: Thermal conductivity of baseline RP-2, $0.7 \%, 1.5 \%$, and $3.0 \%$ PE-CVD coated aluminum nanofuel after three months of storage indicating the ability to easily redisperse the nanoparticles after storage.

over a three-month period would demonstrate a stable nanoparticle suspension that resists agglomeration and subsequent settling. Thermal conductivity data conducted over the three-month period is presented in Figure 14.

As is shown in Figure 14, the thermal conductivity of the baseline RP-2, 1.5\%, and 3.0\% samples was repeatable over the three-month period and exhibited a $2.6 \%$ relative standard deviation at $3.0 \%$ volume fraction. The repeatable thermal conductivity over a three-month storage period demonstrated a nanoparticle suspension that was easily redispersed due to stabilizing the aluminum nanoparticles from agglomeration and supports the data presented in Figure 9. 
3.4. Combustion Enthalpy Evaluation. The volumetric enthalpy of combustion, $\Delta H_{\text {fuel,vol }}$, of PE-CVD coated and uncoated aluminum nanofuel samples at a concentration of $0.7 \%, 1.5 \%$, and $3.0 \%$ by volume was determined by bomb calorimetry and was calculated from (3), where $C_{\text {cal }}$ is the heat capacity of the bomb calorimeter, $\Delta T$ is the temperature change of the bomb calorimeter, $m_{\text {gel }}$ is the mass of the gelatin capsule used to hold the liquid sample, $\Delta U_{\text {gel }}$ is the internal energy of combustion of the gelatin capsule, $L_{\text {wire }}$ is the length of ignition wire combusted during the bomb calorimetry trials, $\gamma_{\text {wire }}$ is the combustion energy of the wire per unit length, $\Delta n$ is the change in the number of moles of gaseous species, $R$ is the universal gas constant $(8.3145 \mathrm{~J} / \mathrm{molK}), \rho_{\text {fuel }}$ is the density of the fuel sample, and $m_{\text {fuel }}$ is the mass of the fuel sample:

$$
\begin{aligned}
& \Delta H_{\text {fuel,vol }} \\
& \quad=\frac{\left(C_{\text {cal }} \Delta T-m_{\text {gel }} \Delta U_{\text {gel }}-L_{\text {wire }} \gamma_{\text {wire }}+\Delta n R T\right) \rho_{\text {fuel }}}{m_{\text {fuel }}} .
\end{aligned}
$$

Experimentally determined volumetric combustion enthalpies of PE-CVD coated and uncoated aluminum nanofuel samples that were stored for one month are presented in Figure 15.

As shown in Figure 15, the volumetric enthalpy of combustion of the PE-CVD coated aluminum nanofuels increased with increasing volume concentration, reaching $0.9 \%$ enhancement at $3.0 \%$ volume fraction. Conversely, uncoated $0.7 \%$ and $1.5 \%$ volume fractions did not improve the volumetric combustion enthalpy of the RP-2 fuel, while the uncoated $3.0 \%$ nanofuel sample exhibited $0.3 \%$ improvement in volumetric combustion enthalpy. Furthermore, statistical analysis of the combustion energy data using a $t$-test, assuming unequal variance, suggests that the measured improvement of the $3.0 \%$ volume fraction PE-CVD coated sample is within a $90 \%$ confidence interval. Thus, the statistical analysis of the volumetric enthalpy of combustion suggests that the observed improvement in energy density of the PE-CVD coated samples was statistically significant.

3.5. Nozzle Erosion Testing. After 25 hours of erosion testing, the nozzle was placed in the evaluation test loop and water was pumped through the nozzle at flow rates varying from 2.5 to $15 \mathrm{GPH}$ in $2.5 \mathrm{GPH}$ increments. The pressure differential across the nozzle was measured in three trials. The discharge coefficient, $C_{d}$, of the nozzle was determined by (4), where $\Delta P_{\text {theor }}$ is the theoretical pressure difference of the nozzle at the given flow rate and $\Delta P_{\text {meas }}$ was the measured pressure difference. The theoretical pressure difference was calculated from (5), where $\dot{m}$ is the mass flow rate of water, $D$ is the diameter of the nozzle $(1 \mathrm{~mm}), \rho$ is the density of water, and $d$ is the ratio of the nozzle diameter to the upstream pipe diameter (0.16):

$$
\begin{aligned}
C_{d} & =\frac{\sqrt{\Delta P_{\text {theor }}}}{\sqrt{\Delta P_{\text {meas }}}} \\
\Delta P_{\text {theor }} & =\left(\frac{4 \dot{m}}{\pi D^{2} \rho}\right)^{2} \frac{\rho\left(1-d^{4}\right)}{2} .
\end{aligned}
$$

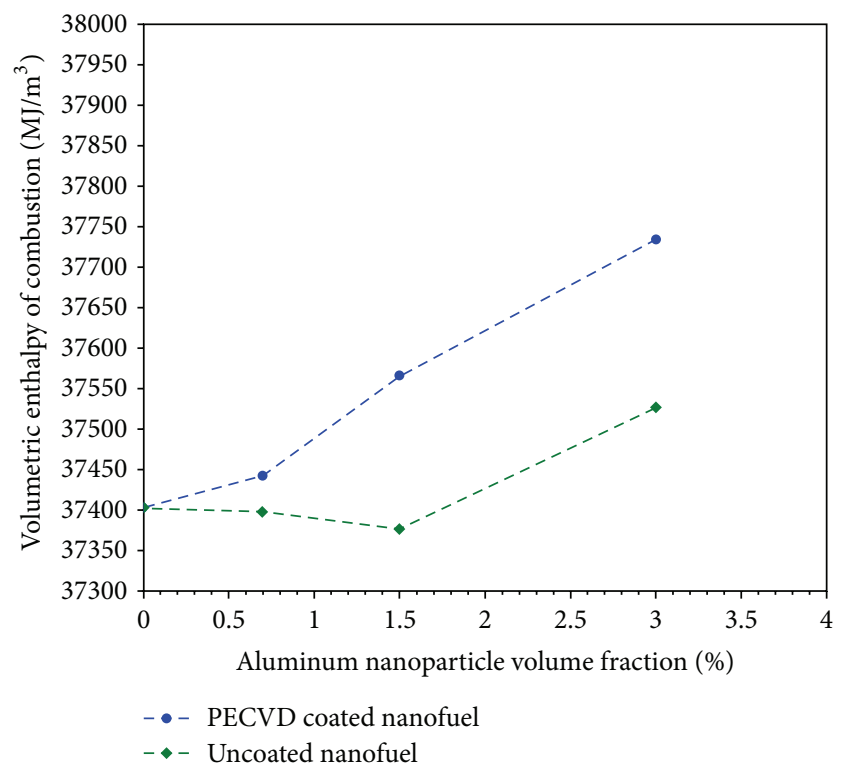

FIGURE 15: Volumetric combustion enthalpy of PE-CVD coated and uncoated aluminum nanofuel samples.

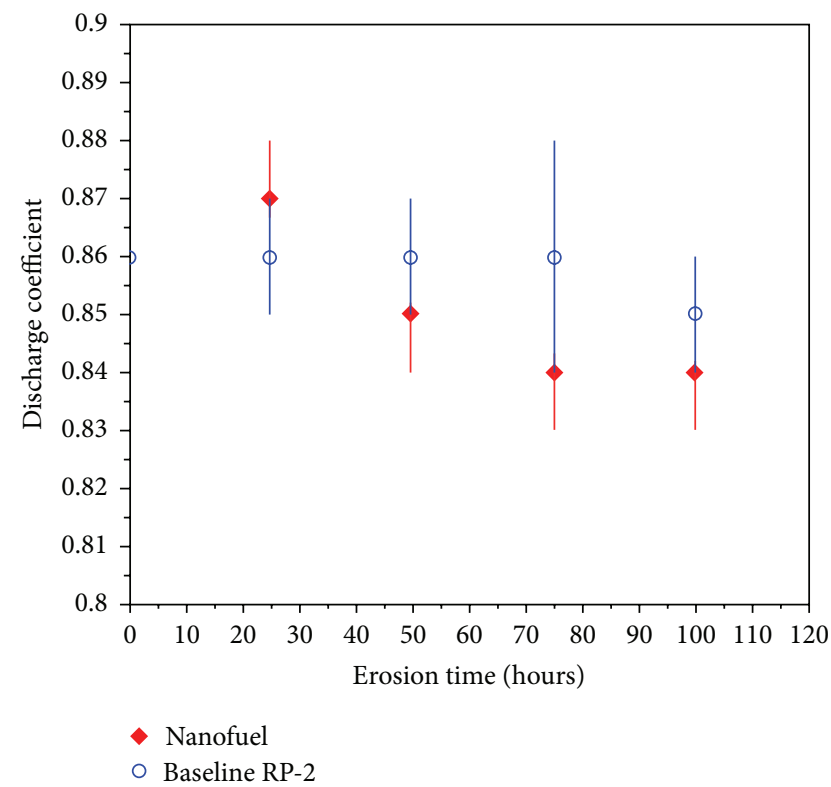

FIGURE 16: Nozzle discharge coefficients throughout the 100 hours of erosion testing indicating negligible change in discharge coefficient.

The discharge coefficients of the nozzle tested with baseline RP-2 fuel and $0.5 \%$ volume fraction nanofuel throughout the 100-hour erosion test are presented in Figure 16.

As is shown in Figure 16, after 100 hours of erosion testing, the discharge coefficient of the nozzle tested with nanofuel reduced by $2 \%$ while the baseline RP- 2 fuel decreased by $1 \%$ indicating a negligible change in discharge coefficient for both samples. The error bars in Figure 16 represent one standard deviation in the measured discharge coefficient over multiple experimental trials. Optical microscopy images of 


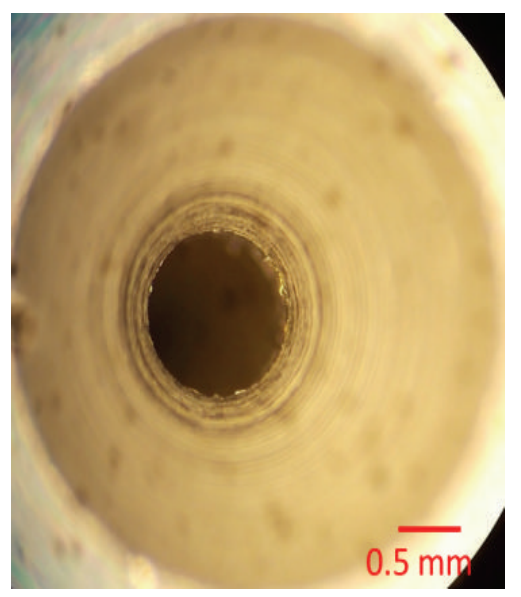

Nozzle discharge $(t=0$ hours)

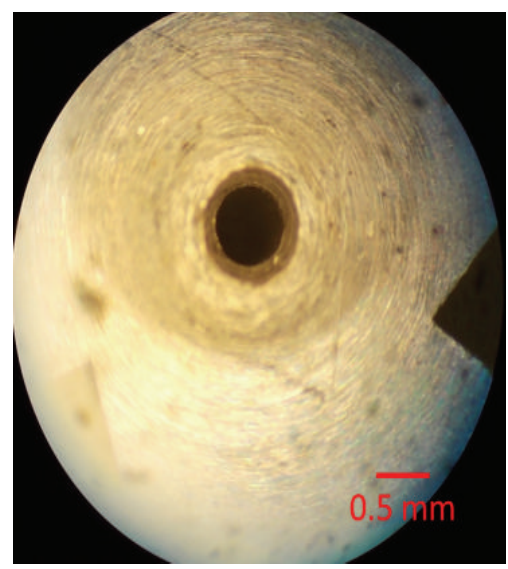

Nozzle inlet $(t=0$ hours $)$

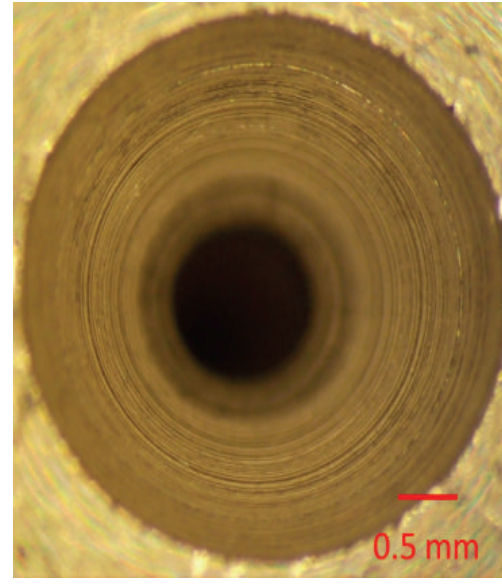

Nozzle discharge, nanofuel ( $t=100$ hours)

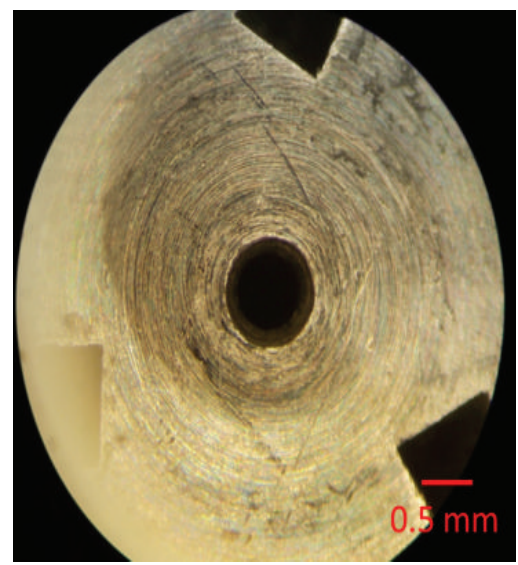

Nozzle inlet, nanofuel $(t=100$ hours $)$

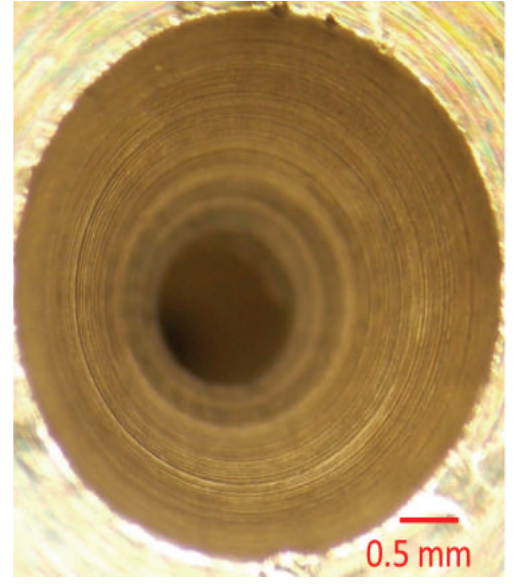

Nozzle discharge, RP-2 fuel ( $t=100$ hours)

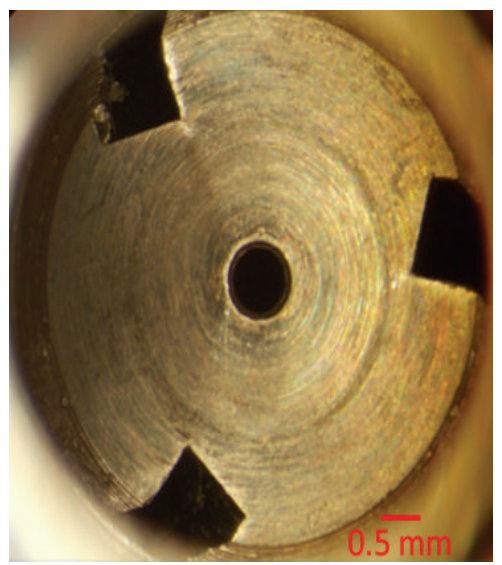

Nozzle inlet, RP-2 fuel ( $t=100$ hours)

FIGURE 17: Optical microscopy images of nozzle discharge and inlets at initial conditions and after 100 hours of erosion testing exhibiting no significant erosion damage.

the nozzle discharge and inlet, prior to testing and after 100 hours of erosion testing, are presented in Figure 17.

As is shown in Figure 17, the diameter of the nozzle discharge and inlet remained constant after 100 hours of erosion testing. However, additional wear was noticed in the inlet of the nanofuel tested nozzle after 100 hours of erosion testing. The additional wear in the nozzle inlet was suspected to increase the roughness of the inlet, thereby increasing the coefficient of friction and subsequently reducing the discharge coefficient, as is observed in Figure 16. However, the change in discharge coefficient between the nanofuel tested nozzle and baseline RP-2 tested nozzle was insignificant after 100 hours of pumping the fuel at a pressure differential of 200 PSI indicating that the nanofuel did not increase the erosion rate of fuel injector components.

3.6. Ignition Delay Time Measurements. To evaluate the effect of adding aluminum nanoparticles to the combustion kinetics of RP-2 fuel, spray ignition delay times were measured in a constant volume combustion chamber. Spray ignition delay times at temperatures ranging from 600 to $800 \mathrm{~K}$ for baseline RP-2 fuel, 1.5\% PE-CVD coated aluminum nanofuel, and 1.5\% uncoated aluminum nanofuel are presented in Figure 18.

The spray ignition delay time for the PE-CVD coated aluminum nanofuels is $10-20 \%$ longer than baseline RP-2 fuel, which is considered within an acceptable deviation. The ignition delay times of the uncoated RP-2 nanofuel samples were approximately $50-100 \%$ longer than the baseline RP2. The combustion process is divided into three major steps: evaporation, mixing, and gas-phase chemical reaction. It was hypothesized that the uncoated sample formed agglomerates that reduced the evaporation rate of the RP-2 fuel, which reduces the kinetics of the combustion process. On the other hand, the negligible change in ignition delay time for the PECVD coated aluminum nanofuel sample provides evidence to support the conclusion that the PE-CVD coating reduces agglomeration and permits the fuel to evaporate and maintain combustion kinetic characteristics while simultaneously releasing more energy as determined in the combustion enthalpy evaluations. 


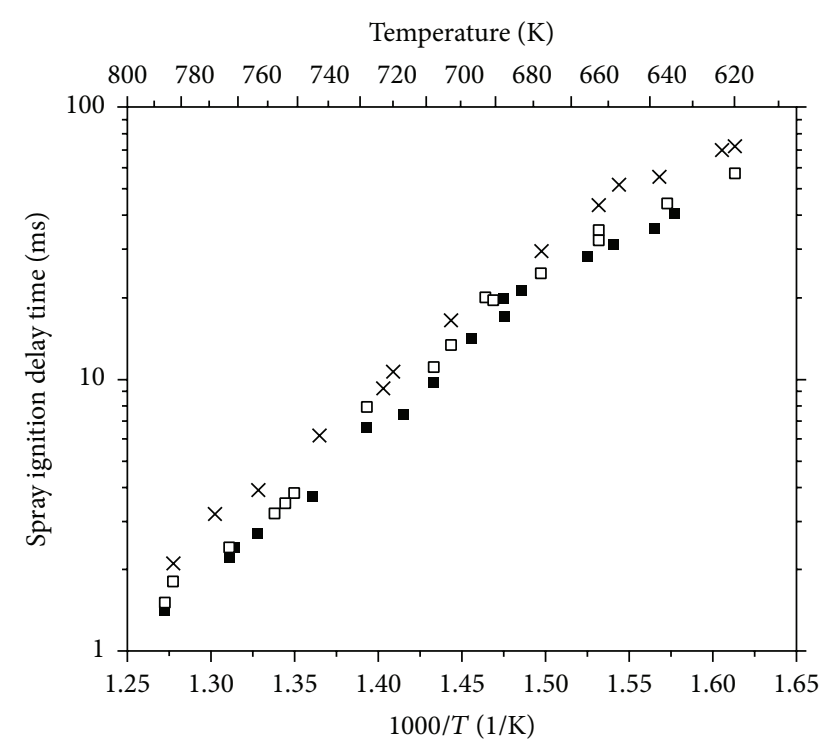

Fuel spray injected into 20 atm heated air - RP-2

口 $1.5 \%$ coated $n A l / R P-2$

$\times 1.5 \%$ uncoated $\mathrm{nAl} / \mathrm{RP}-2$

FIGURE 18: Spray ignition delay time results demonstrating a 10-20\% increase in ignition delay time for the PE-CVD coated aluminum nanofuel and a $50-100 \%$ increase in ignition delay time for the uncoated counterpart.

\section{Conclusions}

Utilizing nanoparticle technology to improve the thermal performance and energy density of fuels can help meet the objectives of improving mission capabilities of aircraft but must be passivated from oxidation and stabilized from agglomeration to ensure the functionality of the fuel is not compromised. Through our research, a passivating $6 \mathrm{~nm}$ thick coating that stabilizes individual nanoparticles was demonstrated by the PE-CVD coating process. Once dispersed into RP-2 base fuel, the nanoparticles exhibited retention of particle size over a five-month storage period, thereby demonstrating stability from agglomeration. Additionally, the thermal conductivity and volumetric enthalpy of combustion of the PE-CVD coated aluminum nanofuel at a concentration of $3.0 \%$ by volume exhibited $17.7 \%$ and $0.9 \%$ improvement, respectively, compared to the baseline RP-2 fuel. At an equivalent concentration, uncoated aluminum nanofuel exhibited $0.3 \% \mathrm{imp}$ rovement in volumetric enthalpy of combustion compared to the baseline RP-2 fuel. The greater improvement in the volumetric enthalpy of combustion between the PE-CVD coated and uncoated aluminum nanofuel indicates that the PE-CVD coating protected the aluminum from oxidation, thereby providing a greater amount of combustible aluminum per mass of nanofuel. Furthermore, the PE-CVD coated aluminum nanofuel exhibited a negligible $1 \%$ reduction in the discharge coefficient of a $1 \mathrm{~mm}$ stainless steel nozzle compared to baseline RP-2 fuel after 100 hours of erosion testing at pressure differential across the nozzle of 200 PSID. Finally, the ignition delay time of the PE-CVD coated aluminum nanofuel and uncoated aluminum nanofuel at a concentration of $1.5 \%$ by volume exhibited an increase in ignition delay time of 10$20 \%$ and 50-100\%, respectively, compared to the baseline RP2 fuel. Thus, the larger increase in ignition delay time for the uncoated sample compared to the PE-CVD coated sample indicates that the agglomeration of the uncoated nanoparticles affected the ignition process. As a result, the passivation and stabilization of aluminum nanoparticles by the PE-CVD coating method demonstrated that nanoparticle technology can be utilized to improve the thermal performance and energy density of fuels.

\section{Conflict of Interests}

The authors declare that there is no conflict of interests regarding the publication of this paper.

\section{Acknowledgments}

The authors thank the United States Air Force for their support of these developments under Contract no. FA930013-M-1007. Additional support was provided by the National Science Foundation under Grant no. CBET GOALI no. 1132220.

\section{References}

[1] P. De Bock and B. Gerstler, Thermal Challenges in Today's Commercial and Military Aircraft, Electronics Cooling, 2011.

[2] R. A. Bhogare and B. S. Kothawale, "A review on applications and challenges of nano-fluids as coolant in automobile radiator," International Journal of Scientific and Research Publications, vol. 3, no. 8, 2013.

[3] Y. Gan and L. Qiao, "Combustion characteristics of fuel droplets with addition of nano and micron-sized aluminum particles," Combustion and Flame, vol. 158, no. 2, pp. 354-368, 2011.

[4] M. Jones, C. H. Li, A. Afjeh, and G. Peterson, "Experimental study of combustion characteristics of nanoscale metal and metal oxide additives in biofuel (ethanol)," Nanoscale Research Letters, vol. 6, no. 1, article 246, 2011.

[5] M. R. Mitchell, R. E. Link, M.-J. Kao, C.-C. Ting, B.-F. Lin, and T.-T. Tsung, "Aqueous aluminum nanofluid combustion in diesel fuel," Journal of Testing and Evaluation, vol. 36, no. 2, Article ID 100579, 2008.

[6] A. Kraynov and T. E. Müller, Concepts for the Stabilization of Metal Nanoparticles in Ionic Liquids, InTech Open Access, 2011.

[7] M. J. Meziani, C. E. Bunker, F. Lu et al., "Formation and properties of stabilized aluminum nanoparticles," ACS Applied Materials \& Interfaces, vol. 1, no. 3, pp. 703-709, 2009.

[8] R. J. Helmich and K. S. Suslick, "Chemical aerosol flow synthesis of hollow metallic aluminum particles," Chemistry of Materials, vol. 22, no. 17, pp. 4835-4837, 2010.

[9] A. Shahravan, T. Desai, and T. Matsoukas, "Passivation of aluminum nanoparticles by plasma-enhanced chemical vapor deposition for energetic nanomaterials," ACS Applied Materials \& Interfaces, vol. 6, no. 10, pp. 7942-7947, 2014.

[10] A. Shahravan, T. Desai, and T. Matsoukas, "Controlled manipulation of wetting characteristics of nanoparticles with dry-based plasma polymerization method," Applied Physics Letters, vol. 101, no. 25, Article ID 251603, 2012. 
[11] H. M. Roder, "A transient hot wire thermal conductivity apparatus for fluids," Journal of Research of the National Bureau of Standards, vol. 86, no. 5, pp. 457-493, 1981.

[12] J. Eapen, R. Rusconi, R. Piazza, and S. Yip, "The classical nature of thermal conduction in nanofluids," Journal of Heat Transfer, vol. 132, no. 10, Article ID 102402, 2010. 

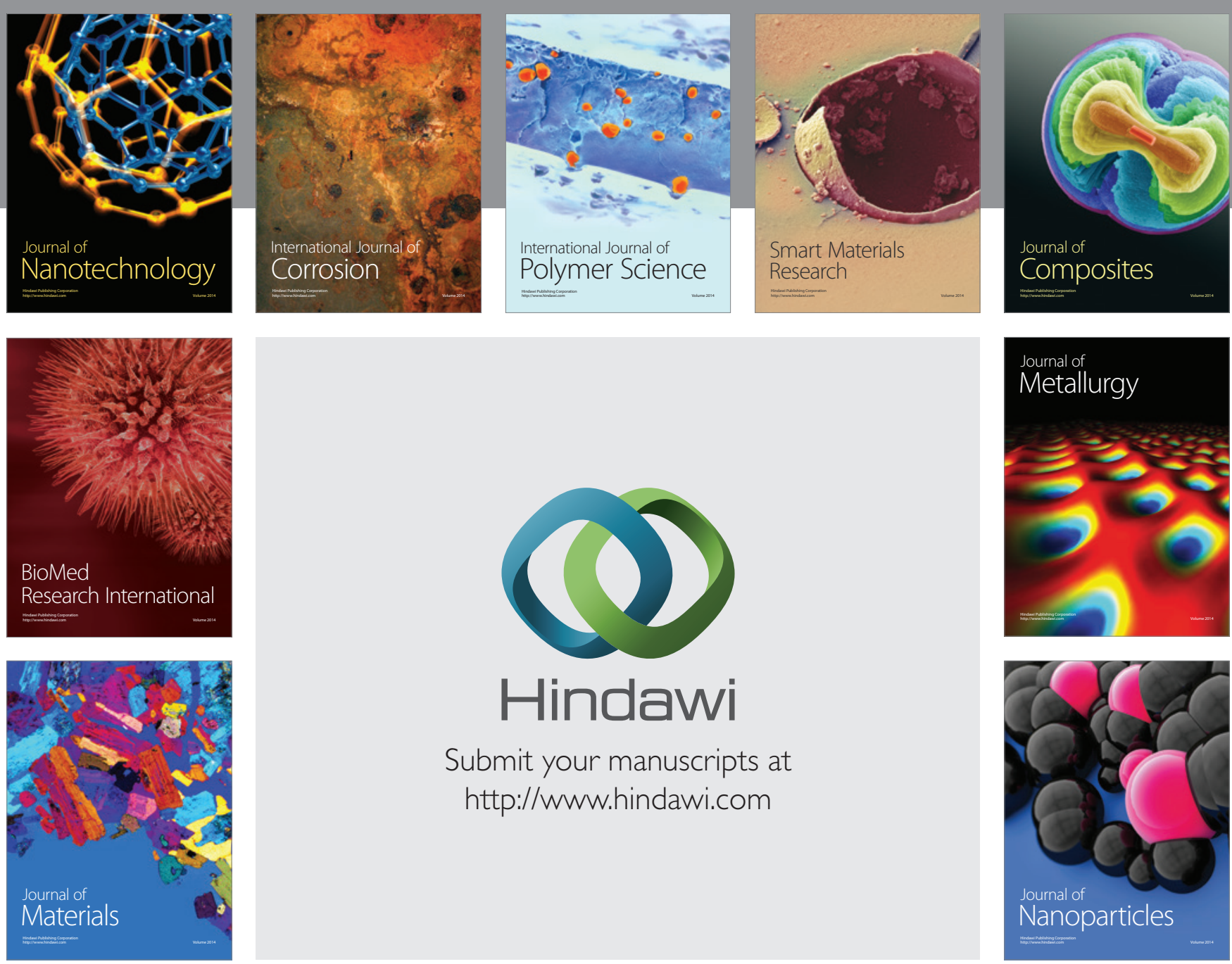

Submit your manuscripts at http://www.hindawi.com
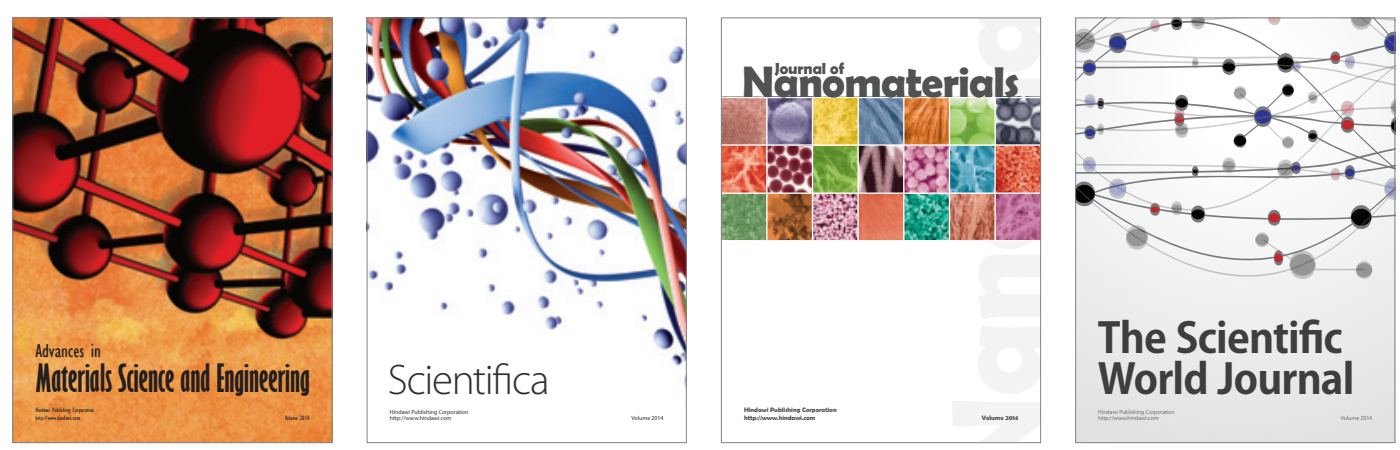

\section{The Scientific World Journal}
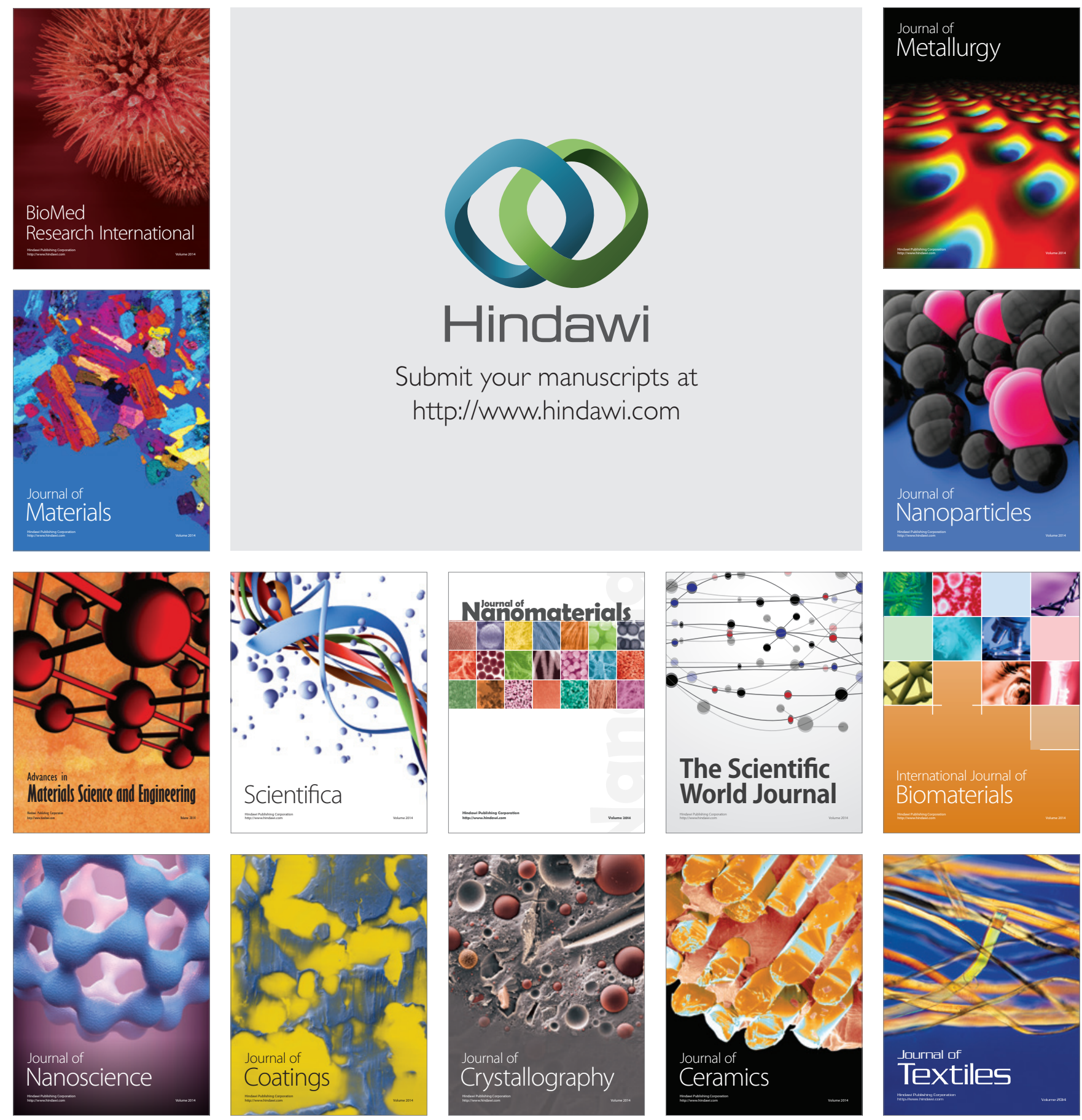